\title{
El periodismo narrativo* o una manera de dejar huella de una sociedad en una época*
}

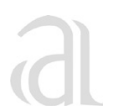

Andrés Puerta ${ }^{* * *}$

Recibido: 15 de octubre de 2010

Aprobado: 2 de febrero de 2011

\section{Resumen}

El periodismo y la literatura se han nutrido y fecundado, han tenido relaciones promiscuas e incestuosas. Para ambas disciplinas ha sido importante tomar prestados y hasta robarse recursos de la otra. El único ganador ha sido el lector que ha podido disfrutar de mejor literatura y mejor periodismo. Eso sí, hay que tener claro que ha habido muchos intentos fallidos para ambos lados, que terminan en un fracaso rotundo de textos que no son ni periodísticos ni literarios.

El buen periodismo también puede convertirse en literatura. El periodismo y, en especial, el periodismo narrativo es una forma de escritura que por sus características, que incluyen encontrar personajes, recrear acciones y contextos, ha sido un modo para mantener una memoria viva de las civilizaciones, una historia que palpita y está viva en esos papeles amarillentos, que cobran validez cada que alguien se dedica a estudiarlos.

En la función de retratar la historia, el principal exponente ha sido la crónica, uno de los géneros que más ha aportado al desarrollo de la narrativa en Colombia y América Latina. Desde los Cronistas de Indias hasta los Nuevos Cronistas de Indias ha habido un intercambio entre la literatura y el periodismo que ha generado productos exitosos como El Carnero, de Juan Rodríguez Freile; el trabajo de Gabriel García Márquez; el desarrollo de movimientos como el Modernismo; épocas y formas de narración como las novelas denominadas de la Violencia. En nuestros días se ha recibido un impulso con un grupo de escritores que intentan reflejar la realidad de nuestro continente con la búsqueda de una voz personal que deja testimonio de una época.

Palabras clave: periodismo, literatura, periodismo narrativo, crónica, reportaje, perfil, testimonio, entrevista, géneros periodísticos, Cronista de Indias, Nuevos Cronistas de Indias.

\footnotetext{
El periodismo narrativo es periodismo porque, aunque utilice diversas técnicas y distintos recursos, no inventa nada, porque en él está presente el compromiso de informar, y es narrativo porque busca contar historias, hacerlas entretenidas para los lectores y con tal grado de profundidad que se conviertan en un reflejo de su época. La narración fundamenta su estructura en las acciones, en los verbos, y es perfectamente compatible con la descripción, que determina su fuerza en los adjetivos y en los sustantivos. Narrar es detallar las acciones de unos personajes en un lugar determinado, una buena narración no puede abstraerse del contexto. Se prefiere este concepto, por encima de otro como Periodismo literario por la posibilidad que ofrece la narración de captar y dejar huella de las acciones humanas, a través de géneros como el reportaje, la crónica, la entrevista, como género en sí, el perfil y el testimonio.

Este artículo de investigación científica y tecnológica hace parte de la investigación "Una recuperación del olvido para el escritor de los olvidados. Análisis del periodismo narrativo de José Antonio Osorio Lizarazo", financiada con recursos propios.

"* Comunicador Social-periodista, magíster en Literatura Colombiana. Investigador en las áreas de periodismo, literatura, periodismo narrativo y redacción de textos. Docente de tiempo completo de la Universidad de Medellín. Correo electrónico: andrespuerta@ udem.edu.co.
} 


\title{
Narrative Journalism or a Way of Leaving a Mark of a Society from a Period of Time
}

\begin{abstract}
Journalism and literature have nourished and fecundated themselves and have been involved in promiscuous and incestuous relationships. Mutual borrowing and theft have been important for both disciplines. The only winner has been the reader who has been able to enjoy better literature and journalism. However, we should understand that there have been many failed attempts from both sides ending in a total failure for texts which are neither journalistic nor literary works. Forms of a good journalism can also become a way of literature. Journalism (narrative journalism, especially) is a way of writing which, due to its specific characteristics (including finding characters, recreating actions and contexts) has been a way of keeping a living memory of civilizations, a beating story, and is alive in those yellowish papers which become valid every time someone tries to study them.

When talking about representing history, the main genre has been the report which is one of the genres with the highest contribution to narrative development in Colombia and Latin America. From the Indias reporters to the new Indias reporters, an exchange between literature and journalism has occurred generating successful results such as El Camero written by Juan Rodríguez Freile, Gabriel García Márquez's work, development of movements such as the Modernism, times and forms of narration such as the novels known as Violence Novels. In our days, an impulse has been noticed with a group of writers trying to reflect reality of our continent in the search for a personal voice to give testimony of a specific period of time.
\end{abstract}

Key words: journalism, literature, narrative journalism, report, interview, profile, testimony, journalistic genres, cronista de Indias, Nuevos Cronistas de Indias. 
La literatura es una noticia que siempre es noticia EZRA POUND

La literatura y el periodismo han tenido una relación estrecha, unos lazos que las han emparentado y enriquecido. Ese vínculo se hace más claro en el Nuevo Periodismo, que los norteamericanos dicen haber inventado, pero que ya estaba latente en la obra de Daniel Defoe ${ }^{1}$, en el Diario del año de la peste; en la de José Martí, y, más contemporáneamente, en el Relato de un Náufrago, ${ }^{2}$ de Gabriel García Márquez. Este tipo de periodismo se vale de unas técnicas similares a las de la literatura, como contar el relato escena por escena; el manejo del tiempo y la tensión para crear atmósferas y dar cuenta de los hechos que los ocupan. Inclusive, ambas son construcciones del lenguaje y a él se deben. El periodismo narrativo tiene el compromiso con la información, pero, además, con el componente estético.

Es cierto que, como han planteado escritores y teóricos, los escritos en los periódicos envejecen muy rápido; pero tienen una forma particular de envejecer, en tanto son una muestra de lo social, una manera para transmitir el conocimiento. El periodismo narrativo tiene, además, la particular característica de trascender en el tiempo; se puede leer una buena crónica de hace mucho tiempo e identificar todos los elementos de validez que se encuentran en un buen relato literario, en el que se establece un diálogo entre el lector y el escritor de cualquier época.

\section{Periodismo con una mirada subjetiva}

Un periodismo que toma decisiones como el tipo de narrador que va a utilizar, que desecha gran cantidad de información, que incorpora anécdotas

Daniel Defoe (1660 - 1731) fue un escritor, periodista y espía inglés, famoso por su novela Robinson Crusoe. Su novela Diario del año de la peste aplica la técnica periodística: recurre a cifras, a estadísticas, a entrevistas para presentar un panorama de Londres devastado por la peste.

2 Este texto es considerado una de las piezas maestra del periodismo narrativo, inclusive ha sido estudiado como un ejemplo para los estudiosos del testimonio, como un género no canónico que busca darle voz a los que no la han tenido. y detalles que, al periodismo de primera plana, pueden parecer insignificantes; un periodismo que reconstruye atmósferas, lugares, personajes; un periodismo en el que se notan las particularidades del periodista que lo escribe; que escoge temáticas sin necesidad de que provengan de historias espectaculares, necesariamente tiene una mirada subjetiva.

La profesora y periodista Patricia Nieto ${ }^{3}$ plantea, en el prólogo del libro Escribiendo historias. El arte y el oficio de narrar en el periodismo, del escritor y periodista Juan José Hoyos ${ }^{4}$ (2003), que:

Los combates por la narración en el periodismo se libran en la arena de lo subjetivo, y ello sugiere que los periodistas desean conquistar la ambigua franja donde se unen lo público con lo político, lo colectivo con lo privado, lo íntimo, lo individual. Esta tendencia, subversiva si se quiere, se ha extendido sobre campos antes exclusivos de literatos, antropólogos, historiadores y filósofos. (Nieto. En: Hoyos, 2003, p. 5).

En el periodismo narrativo es importante la interpretación, esa parte subjetiva que menciona Patricia Nieto (2003). Las crónicas, como los cuentos, los reportajes, como las novelas, no son la realidad, son una representación de esa realidad, y se acercan a lo que George Stainer ${ }^{5}$ (2000) ha denominado posficción, ese campo en el que hay una delgada línea entre la ficción y lo fáctico. Eso sí, con la claridad absoluta de que en el periodismo no hay lugar para aquello que se inventa, no cabe la mentira.

El asunto de la subjetividad en el periodismo parece un equívoco, si miramosel periodismo desde su concepción tradicional o si nos apegamos a la definición del periodismo informativo, pero el periodismo va más allá de la noticia, en

3 Periodista antioqueña, estudiosa de los géneros periodísticos, ganadora del Premio Nacional de Periodismo Simón Bolívar, de los Premios Nacionales de Cultura Universidad de Antioquia y del Premio Latinoamericano de Periodismo José Martí.

4 Escritor y periodista antioqueño, estudioso del periodismo narrativo y del reportaje.

Francis George Steiner (París, 23 de abril de 1929), crítico y teórico de la literatura y de la cultura, y escritor. Ha sido uno de los teóricos que ha propuesto la consideración del estudio de géneros no canónicos, como la historia, a través del concepto de la Posficción. 
él están presentes otros géneros en los que es necesario el componente subjetivo, la mirada, la interpretación, el análisis, la descripción del periodista que los realiza.

El buen periodismo, ese que han llamado Nuevo Periodismo, Periodismo Literario, Literatura de Hechos, Literatura de no Ficción, Periodismo Personal, Paraperiodismo o el arte de narrar en el periodismo, como lo definiría Juan José Hoyos (2003), es subjetivo y omnívoro, porque toma elementos de las distintas disciplinas de las ciencias sociales y las distintas disciplinas de las ciencias sociales toman elementos de él. La noticia deja de ser objetiva, la objetividad como la verdad son conceptos relativos, lo que busca este tipo de periodismo es ser preciso, consultar el mayor número de fuentes posibles para acercarse al hecho, hacer una investigación responsable, contrastar distintos tipos de fuentes y, por supuesto, que el periodista interprete los datos, que no sea un agente pasivo, un simple transmisor de información.

Uno de los valores periodísticos que actualmente sufre toda suerte de ataques es el de la objetividad. La objetividad se puede entender en dos sentidos: como una búsqueda de la verdad, o como un total apartamiento emocional e ideológico del periodista frente a la noticia. No hay duda de que la segunda es, al menos entre seres humanos, un mito. Toda noticia, todo reportaje, está lleno de decisiones de tipo personal del periodista [...] El contenido de objetividad como cualidad periodística se ha renovado en el sentido que se lo entiende ahora como la actitud profesional a favor de la verdad. (Gordimer, 1997, p. 30).

La premio Nobel de 1991, Nadime Gordimer, entiende que el periodismo no puede transmitir la realidad, únicamente puede representarla. Tiene claro que las noticias o las crónicas o los reportajes son escritos por seres humanos, que tomarán decisiones que afectarán el escrito: ¿qué voy a contar? ¿Cómo lo voy a contar? ¿Qué enfoque le daré al texto? ¿Qué tipo de fuentes utilizaré? ¿Cuál género será el más adecuado para mi historia? Estos interrogantes condicionan el texto que se produce y lo que le llegará a los lectores; pero también entiende que estas decisiones deben ser responsables y se debe buscar la mayor precisión posible.

Oriana Fallaci ${ }^{6}$, en una entrevista con la revista Time, ratificó estos conceptos; afirmó que odiaba la palabra objetividad, que prefería referirse a lo "correcto" y a lo "honesto", y agregó: "Mis entrevistas nunca son frías. Porque me enamoro de la persona que está frente a mí, así la odie. Una entrevista es para mí una historia de amor. Es una pelea. Es un acto sexual" (Fallaci, 1975, 20 de octubre. Time. p. 47).

Tomás Eloy Martínez (2006) también ha reflexionado sobre el tema de la objetividad y ha expresado: "De todas las vocaciones del hombre, el periodismo es aquella en la que hay menos lugar para las verdades absolutas. La llama sagrada del periodismo es la duda, la verificación de los datos, la interrogación constante" (Martínez, 2006, p. 38). En el periodismo siempre hay que tener una determinada inclinación hacia la duda, hacia la confirmación, hacia la vivencia.

\section{Relaciones incestuosas entre el periodismo y la literatura}

En una sociedad en la cual los estudiantes aprenden que hay dos clases de escritura, la ficción y el periodismo, y que el periodismo es en general una prosa opaca, hacer periodismo literario es un negocio difícil.

Norman Sims

El periodismo y la ficción, asociada a literatura, son dos universos diferentes, pero hay producciones en las que se presenta un amplio escenario para indagar cómo pueden encontrarse la literatura y lo fáctico, en textos periodísticos que pueden tener valor estético.

\footnotetext{
Fue una de las periodistas más destacadas de su tiempo, exploró el periodismo narrativo. Sobre todo, se concentró en la entrevista, en la que se destacó por la facilidad para ganarse la confianza de sus entrevistados y, de esta manera, consiguió que sus entrevistas fueran más parecidas al diálogo que al interrogatorio.
} 
El periodismo, como una modalidad de discurso, comparte distintas características con la escritura que se considera tradicionalmente como literaria, es decir, como arte del lenguaje. El periodismo no es una imagen que refleja la realidad, sino una construcción, una representación de ésta. Y construcción quiere decir que es una producción discursiva, con todas las características que puede tener una representación de una obra literaria.

La teoría contemporánea de los géneros enseña que el género literario no debe entenderse como un sustrato metafísico. El género no es una esencia, sino un producto histórico: hay géneros que dejan de cultivarse, mientras otros aparecen como resultado de fusiones, mezclas, ensayos o trasgresiones de categorías existentes. En este sentido, géneros como la epopeya son considerados en desuso, y géneros como la crónica o el reportaje podrían considerarse como literarios, a partir de sus relaciones, sus aportes, sus construcciones comunes. Además, como plantea Tzvetan Todorov ${ }^{7}$ (1988), "Un nuevo género es siempre la transformación de uno o de varios géneros antiguos: por inversión, por desplazamiento, por combinación" (Todorov, 1988, p.34).

Manuel Silva Rodríguez (2007) habla acerca de las relaciones entre periodismo y literatura y lleva la problemática más allá de lo meramente formal; a través del análisis a la obra de Truman Capote 8 intenta una reformulación del concepto de literatura canónica, inclusive, esboza un intento de ampliación del horizonte estético:

No se trata de trasladar técnicas o procedimientos de un campo a otro, sino de poner en cuestión el concepto mismo de literatura privilegiado por la tradición. A la luz de la noción más convencional de lo que se puede entender como literatura, el traba-

\footnotetext{
Lingüista, filósofo, historiador, crítico y teórico literario de expresión y nacionalidad francesa, nacido en Bulgaria en 1939.

Periodista y escritor estadounidense, su novela A sangre fría (1966) es considerada la precursora del Nuevo Periodismo. En ella, a través de una investigación de más de seis años, el autor reconstruye el asesinato de una familia en Holcomb, Estados Unidos. Este hecho había sido una noticia de unos pocos renglones en la prensa informativa, pero Capote aplicó técnicas literarias para hacer un Gran Reportaje, en un género que él mismo denominó Non fiction novel.
}

jo de Capote aparecía como un verdadero oxímoron: novela de no- ficción, o sea, literatura sin invención. (Silva, 2007, p. 67).

Para fundamentar sus planteamientos, Silva Rodríguez (2007) recurre a la opinión de varios teóricos que coincidieron en señalar esas características de fondo y de forma que tiene el periodismo narrativo, y centra su atención en la diferencia entre lo imaginativo y lo imaginario. En el periodismo puede haber textos muy imaginativos, que requieren un gran esfuerzo intelectual de sus autores. Lo único que quedaría excluido sería lo imaginario, lo ficcional:

La novela de Capote, pues, puso al descubierto que, para crear literatura, para que un texto adquiera valor literario, no necesariamente tiene que tratar de cosas imaginarias, hablar de lo que podría ser, sino que puede tomar como material lo que ya fue, lo existente $[\ldots]$ en arte, y por lo tanto en literatura, importa menos el qué (en este caso su naturaleza, si es ficticio o no) que el cómo. Importa más cómo está configurado el material, es decir cómo se organizan los elementos y conforman un todo coherente, que de dónde procede, si de la imaginación del autor o de la realidad fáctica. En otros términos, recordando la estética de Adorno, podríamos decir que aquello que inventa o descubre el autor es el cómo, la forma adecuada a su material. (Silva, 2007, p. 67).

El hecho de no tener ficción no imposibilita a un texto para considerarse literario; hay autores que toman la decisión consciente de no inventarse nada porque es el recurso que consideran más válido para presentar sus construcciones lingüísticas y la falta de ficcionalidad no les impide poseer un componente estético y artístico.

Silva Rodríguez, inclusive, se remonta a las reflexiones de los griegos y plantea unos posibles errores de interpretación de la crítica a las teorías planteadas por los clásicos, y formula nuevas interpretaciones que apoyarían el hecho de que algunos textos periodísticos puedan considerarse literatura.

Pese a que se ha prestado más atención a la parte en que Aristóteles dijo que el 
poeta escribe sobre aquello que podía ser, el mismo filósofo agregó después lo siguiente: "De todo lo dicho se desprende con claridad que el poeta debe ser más un hacedor de tramas que de versos [...] Y si en algún caso se hace objeto de su poesía sucesos reales, no por ello es menos poeta". (Silva, 2007, p. 67).

La labor, en este caso, del periodista está en encontrar esos elementos poéticos en la realidad, en lo cotidiano, en las tragedias y vivencias de los personajes comunes.

Otra reflexión de Silva Rodríguez (2007) tiene que ver con la recepción de la obra de arte. De nuevo, a partir de los textos de Truman Capote, y de la subversión a esta problemática estética: "En efecto, se trata de la reafirmación de que por fuera de los cánones y de la teoría que pretenden predeterminar qué es arte, en última es en el momento del contacto del receptor con la obra cuando se reconoce la calidad estética o no de la creación" (Silva, 2007, p.67).

La estética y la recepción de las obras estéticas no pueden ser estáticas; hay momentos en los que es necesario analizar tendencias diferentes a las dominantes, ampliar los horizontes. En el caso colombiano hay ejemplos muy claros; la crítica olvidó la obra de un autor como José Antonio Osorio Lizarazo por tres razones fundamentales:

- Estuvo alejado de la estética dominante de finales del siglo XIX y principios del siglo XX, enmarcada en las ideas conservadoras, que tenían una fuerte nostalgia por lo español y buscaban mantener el privilegio de unos cuantos. Esa estética era defendida por una élite letrada, que estaba en el poder.

- La miopía de la crítica que catalogó como errores y aspectos negativos, elementos que eran definitivos para la construcción de la obra de Osorio Lizarazo. El autor bogotano es pionero en el tratamiento del tema urbano en la literatura colombiana e identifica una serie de características de la trasformación de las ciudades y el impacto sobre sus habitantes, el surgimiento de problemáticas eminentemente urbanas. Osorio Lizarazo utiliza los recursos narrativos más válidos y adecuados, como lo expresa Rafael Gutiérrez Girardot (1982) para construir una narrativa coherente, veraz y verosímil, en la que era necesaria la investigación, los análisis sociológicos, el periodismo de inmersión.

- Los hechos extraliterarios, como trabajar para la dictadura de Juan Domingo Perón y Rafael Leonidas Trujillo hizo que los intelectuales colombianos se distanciaran definitivamente de él y acabaran de justificar ese nefasto e injusto olvido que pesa sobre su cabeza.

Es lamentable que la crítica permanezca inmóvil y anquilosada, y haga que obras prolijas y de una calidad indudable estén en el olvido por la miopía. Para Osorio Lizarazo era más importante ser fiel a la realidad, así tuviera que alejarse de lo bello e ideal y mostrar lo feo y degradado. Esto es fundamental ya que, según expresa Silva Rodríguez (2007):

Como postula Heidegger, la experiencia del arte es un shock a nuestra forma habitual de ver las cosas que nos mueve a verlas de otra manera, en obras como éstas donde no hay ficción su grandeza radica en que aun estando el lenguaje ligado a la realidad efectiva, por la organización total del material que le da cuerpo la obra trasciende el nivel informativo y nos comunica más que los datos escuetos tomados de los hechos reales. Es porque las convenciones estéticas se han roto, que el pensamiento estético más contemporáneo ha trasladado la pregunta de qué es el arte hacia los interrogantes de dónde o cuándo hay arte (Silva, 2007, p. 67).

Estos postulados están en la misma línea que expresa el teórico francés Gerard Genette (1991), en su texto Ficción y dicción, en el que plantea la existencia de un criterio temático y otro formal para la consideración de un texto como literario. Inclusive, piensa que

Por ser un fenómeno plural, la literalidad exige una teoría pluralista que se haga cargo de las diversas formas que tiene el lenguaje de escapar y sobrevivir a su función práctica y producir textos susceptibles de 
reconocimiento y apreciación como objetos estéticos (Genette, 1991, p. 27).

En este postulado es clara la necesidad de no ser estáticos en la apreciación y está la certeza de no determinar la ficción como único criterio para definir la literariedad (eso que le concede su carácter de literario a un texto). Manuel Silva Rodríguez (2007) reivindica estos elementos en la obra de Truman Capote, pero antes de Capote estuvieron Daniel Defoe, Rodolfo Walsh ${ }^{9}$, y también Osorio Lizarazo.

Dentro de esta técnica es importante tener en cuenta la opinión de Germán Santamaría ${ }^{10}$ (1997), uno de los grandes cronistas de las últimas décadas en Colombia, quien describe una metodología importante en la construcción de sus obras de periodismo narrativo

Creo que en el periodismo sí es posible plantear hallazgos estéticos, hallazgos que perduren por la belleza y que les den a los lectores una sensación de espiritualidad, de rabia, de amor, de rechazo, de ira, de violencia, de cuestionamiento o de gran belleza, de gran sutileza, inclusive de dimensión musical (Santamaría, 1997, p. 11).

Esta metodología cumple la premisa que promulgaba Joseph Pullitzer, citado por Velásquez (2005), entre sus reporteros "hazlos reír, hazlos llorar, pero provócales emociones" (2005, p. 91), una manera de observar la escritura, lo literario a través de lo real, y esa premisa de que se pueden construir textos literarios con lo periodístico.

\footnotetext{
9 Según los argentinos es el creador de la Novela de no ficción, su libro Operación masacre que relato los hechos ocurridos en 1956, cuando se presentó un contra-golpe militar a la dictadura de la llamada Revolución Libertadora que fracasó. En un terreno baldío de la provincia Iosé León Suarez, de Buenos Aires, Argentina, son fusilados varios civiles sospechosos de hacer parte del levantamiento. A casi seis meses del hecho, alguien le dice a Rodolfo Walsh que hay un fusilado que vive. Gracias a la investigación, Walsh descubre que son siete los sobrevivientes, los contacta y cuenta su historia.

10 Nació en el Líbano, Tolima, el 24 de enero de 1950. Ha obtenido diversos primeros premios en concursos nacionales e internacionales de cuento, novela y periodismo, entre otros, el Premio Nacional de Periodismo Simón Bolivar en cuatro ocasiones, el internacional Merhengiger de Canadá, el de la Organización Continental Latinoamericana de Estudiantes, (Oclae) y el Iberoamericano de Novela en Chile.
}

Aunque la escribió toda en periódicos y revistas: de Medellín, de Bogotá, de Pereira, de Barranquilla, la suya es de las más genuinas literaturas, de las más sobrias, de las más elegantes, de las más inteligentes, también de las más divertidas y a veces de las más irónicas. Pero no era ficción lo suyo sino pequeñas crónicas, es decir, asuntos de la realidad, del pasar cotidiano [...] cientos de crónicas, de breves ensayos en los que puso, sin excepción, una dosis tal de sensibilidad, de sabiduría natural y de percepción poética, que, 110 años después, no sólo es muy difícil parangonarlos con alguna otra obra en nuestro medio y aun en un medio distinto al nuestro, sino que conservan intactas su lozanía, su frescura juvenil, su delicada y sutil elegancia (Sierra, 2008, p. 6).

El periodismo también ha contribuido al desarrollo de la literatura, por ejemplo, la obra literaria de Luis Tejada está conformada por crónicas, que son piezas sensibles de realidad. Este aporte también lo podemos vislumbrar a través de la lectura de ese fragmento del acta del premio Nobel que le fue concedido a Gabriel García Márquez que dice: "por su obra literaria y periodística". Un premio eminentemente literario que reconoce, además de lo obvio: el aporte de la literatura, la contribución de lo fáctico en la obra de, quizá, el mejor periodista colombiano de todos los tiempos.

William Faulkner ${ }^{11}$, hablando sobre sus novelas afirmó: "Todos mis personajes son gente a la que conozco y sobre la que hice muchas averiguaciones" Uno de los grandes maestros del periodismo narrativo, Gay Talesse, en una entrevista realizada por Boyton (2005), planteó:

Quiero transmitir el asombro de la realidad. Creo que si uno excava lo suficiente dentro de los personajes, éstos se vuelven tan reales que sus historias adquieren un aire imaginario. Parecen de ficción. Yo aspiro evocar la corriente ficcional que fluye bajo el río de la realidad. (2006, p. 19).

\footnotetext{
11 Entrevista a William Faulkner. En: http://www.ciudadseva.com/ textos/teoria/opin/faulkner.htm. Recuperada el 5 de noviembre de 2008.
} 
Personajes reales, transmitir el asombro de la realidad, un literato como Faulkner; un periodista como Talesse, que comparten técnicas narrativas, recursos intercambiables, una relación incestuosa entre el periodismo y la literatura que les ha aportado métodos, maneras de trabajar y de concebir la escritura. Unas relaciones en la que se hace presente la necesidad de la investigación, del periodismo de inmersión, de ese que se hace caminando, metiendo la nariz entre papeles, conversando u observando a alguien mientras hace su trabajo. Ese que requiere mística, pasión y un método juicioso. O un método salvaje para investigar sin mapas ni brújula, y luego escribir con la emoción aún pegada a los dedos.

\section{El periodismo como trasmisor de conocimiento}

Cada noche, después de contarles historias a sus nietas, Somerset Maugham iba hasta la puerta y las miraba una vez más, rendidas al sueño: «Sentía allí que un narrador, en el fondo, no es más que eso: el que apaga la luz». Un cronista, por el contrario, vendría a ser el que la enciende

Julio Villanueva Chang

Cuando se escribe se comparte el saber, la experiencia y lo que se investiga, se establece un diálogo entre el escritor y el lector de cualquier época; en esta conversación interviene el saber y el acervo cultural de cada uno. Por eso uno de los principales fines del periodismo es la transmisión de conocimiento, dejar huella de la sociedad y de la época en la que se escribe. En este propósito cumple un papel fundamental la crónica, desde su etimología: Chronos, tiempo; este género se ha encargado de registrar la sucesión temporal desde que el ser humano adquirió el lenguaje, desde esa feliz conjunción entre lengua y habla.

Se habla de crónica a partir las primeras civilizaciones que intentaron dejar testimonio de sus costumbres. La crónica está presente en la Biblia, en el Génesis, en el principio, rico en tes- timonios. También hay crónica en los griegos y romanos quienes documentaron el esplendor de sus civilizaciones; hablamos de los Cronistas de Indias, quienes maravillaron a Europa con lo que encontraron en el Nuevo Mundo, grandes hombres como Alejandro Magno tenían cronistas a sueldo para registrar sus hazañas.

Mucho se ha criticado al periodismo por tener una fecha de vencimiento muy próxima, por tener una caducidad casi inmediata, pero esa evanescencia temporal desaparece cuando el periodismo que se hace tiene un componente estético y logra capturar el ambiente, las costumbres, la cultura en la que se produce. Por eso, las investigaciones de las ciencias sociales, y hasta de la literatura, comienzan con una revisión de la prensa, por eso podemos sorprendernos frente a una crónica escrita hace varios años.

En la cartilla número 13 del Legado del saber, que publicó la Universidad de Antioquia como parte de la celebración de sus 200 años, llamada Literatura de urgencia, Juan José Hoyos (2003), plantea: "El periodismo ha sido tal vez la actividad humana que, junto con la historia, la literatura y otras artes como el teatro y el cine, les ha permitido de manera más profunda a los hombres conocerse a sí mismos y arrojar luz sobre su propia historia". (Hoyos, 2003, p. 12).

Ese conocimiento nace de la posibilidad de mirar el reflejo de una época, de rastrear las costumbres, los modos de vida, el habla de la gente. Hay corrientes literarias que se imponen y determinan el tipo de literatura que se produce en algunos momentos; por eso el periodismo, ansioso de contar lo que pasa en un lugar determinado, en un tiempo determinado, con el privilegio del aquí y el ahora, constituye una fotografía fundamental, un espejo en el que las generaciones del futuro, cualquier futuro, pueden mirar y conocer lo que sucedía y cómo sucedía. En ese sentido, es necesario que el reportero sea detective, obrero, pero también un sujeto con los sentidos dispuestos a ver, oler, escuchar y capturar una época; un periodista que sea consciente de que no escribe para el momento sino para capturar el momento que más adelante puede ser consultado. Esto sería, como escribió 
Juan Villoro ${ }^{12}$, citado por Julio Villanueva Chang ${ }^{13}$ (2006), "un modo de improvisar la eternidad".

Norman Sims, en Los periodistas literarios o el arte del reportaje personal (1996), plantea que "como los antropólogos y los sociólogos, los reporteros consideran que comprender las culturas es un fin" (1996, P.15). Los periodistas buscan que la acción hable, que sus relatos sean una manera de entender y retratar la cultura en la que viven. El investigador Donaldo Alonso Donado Viloria en su estudio titulado Crónica anacrónica. Un estudio sobre el surgimiento, auge y decadencia de la crónica periodística en Colombia (2003) señala a su vez que: "La crónica es memoria escrita". La crónica y el periodismo, en general, sirven para dejar testimonio de la época en la que se escriben. La escritura permite que esa huella se conserve, que no sea una sustancia etérea que puede evaporarse.

Para lograr estas condiciones se necesita un nuevo periodista. En su definición, Julio Villanueva Chang propone unas nuevas responsabilidades de géneros como la crónica

... para un lector una crónica ya no es tanto un modo literario de «enterarse» de los hechos, sino también una forma de «conocer» el mundo. La crónica se ha vuelto una forma de conocimiento. Un cronista ya no es sólo un escritor de la información. Se necesitaba una definición más ética. Ahora su tarea parece ser contar una historia de verdad y evidenciar los síntomas de su época. Se trata de convertir el dato en conocimiento. (Villanueva Chang, 2006, p. 57).

Convertir el dato en conocimiento es ir más allá de lo estadístico, es responder al componente estético, procurando lograr una asociación que le permita al lector entender y aterrizar una

12 Juan Villoro es uno de los principales cronistas de Latinoamérica, sus textos han sido publicados en América y Europa, sus crónicas tocan temas que van desde el fútbol hasta los Simpson. En su trabajo se destaca la combinación de narración e información, en un entramado narrativo que se relaciona con el ensayo.

13 Julio Villanueva es un periodista peruano, su labor también lo llevó a ser el fundador y director de la revista Etiqueta Negra, una de las más importantes del continente en el periodismo narrativo, en ella publicaron su trabajo grandes figuras como John Lee Anderson y Juan Villoro, pero también sirvió de escuela para nuevos cronistas que pulieron su estilo y encontraron una voz fresca y rigurosa con la tutela de Villanueva Chang. cifra, y al componente informativo, entender que se hace periodismo, y no es suficiente con que se escriba bonito.

Pero no sólo la crónica asume esta responsabilidad. Para establecer la diferencia entre el periodismo perecedero y aquel que trasciende debemos analizar un concepto básico, el de géneros periodísticos. Para el profesor Martínez Albertos, citado por César Mauricio Velásquez, en el Manual de géneros periodísticos (2005) éstos son "aquellas modalidades de creación lingüística, destinadas a ser canalizadas a través de cualquier medio de difusión colectiva y con el ánimo de atender a los dos grandes objetivos de la información de actualidad: el relato de acontecimientos y el juicio valorativo que producen tales acontecimientos", es decir, los géneros periodísticos, independiente del medio en el que se presenten, son formas de creación lingüística en las que es posible opinar, narrar y describir; en ellos hay un autor, con nombre propio; puede existir un narrador, unos personajes, un tiempo, un espacio, como en la literatura.

El concepto de género periodístico, según Velásquez (2005), fue utilizado inicialmente por Jacques Kayser, quien en 1952 veía en este concepto uno de los criterios para la clasificación de los contenidos de la prensa.

La teoría clasificadora de los géneros periodísticos no se creó inicialmente con una preocupación filológica o literaria, sino más bien como una técnica de trabajo para el análisis psicológico de carácter cuantitativo de los mensajes que aparecían en los periódicos, posteriormente se perfiló como una doctrina filológica propia de la sociolingüística, de gran utilidad para hacer valoraciones críticas de carácter literario y lingüístico (Velásquez, 2005, p. 15).

Desde un principio, los géneros periodísticos buscaron definir una literariedad de determinadas formas de ofrecer las noticias, maneras para cumplir con el doble compromiso del contenido: la información y un componente estético: la forma.

Es importe aclarar, eso sí, el planteamiento de Gomis, citado por Velásquez (2005) 
los géneros son modos convencionales de captar y traducir la realidad. Las reglas por las que se rigen son bastantes flexibles y admiten muchas variedades. Lo fundamental, sin embargo, es que cada uno de ellos cumple una función distinta y cubre un sector de ese amplio arco que va desde la noticia al editorial (Velásquez, 2005, p. 16).

Cada género tiene una función y unas características específicas; las noticias se concentran en la respuesta a unos interrogantes, que la teoría ha denominado WS, por sus siglas en inglés; los textos narrativos y descriptivos no abandonan el componente informativo, pero se concentran en otros aspectos formales que le dan gran valor a los verbos, los sustantivos o los adjetivos, según el caso, y existe una tercera corriente, que son los géneros de opinión, que buscan interpretar y orientar, en los que hay una valoración de los hechos.

\section{La crónica, un género que habla español}

La crónica es un género latinoamericano, con fuerte acento colombiano. Aunque tiene un origen remoto, que algunos teóricos ubican en el Génesis de la Biblia e incluso hay quienes lo sitúan en el comienzo de las civilizaciones, en Mesopotamia, en el maravilloso descubrimiento de la historia de Gilgamesh, es en América, en momentos definitivos, donde la crónica recibe un impulso vital.

La crónica es uno de los géneros más ricos, más elaborados, que más relación tiene con la literatura. Es una zona de tránsito libre, en la que confluyen distintas disciplinas: es narrativa, descriptiva y opinativa. En ella hay una búsqueda del rostro humano de la noticia. En la crónica hay una necesidad de buscar unos protagonistas diferentes de la historia, la crónica representa la realidad, y la realidad está plagada de estos nuevos protagonistas; por eso es un género que se convierte en una manera de expresar la vida misma, a través de distintas maneras de narrar.

A pesar de sus libertades y de ser un puerto en el que no se cobran aranceles, la crónica se debe a una representación de la realidad, en la que es necesario un retrato fiel y también un compromiso con la forma.

La crónica exige, por naturaleza, la imaginación e interpretación del periodista, ingrediente indispensable para encontrar el modo, la forma, la estructura más eficaz, más clara de hechos noticiosos, actuales o actualizados, donde se narra algo, al propio tiempo que se juzga. La narración que tiene una crónica es el toque personal que le impone el cronista, quien da su apreciación personal, mas nunca tergiversa la realidad.

La noticia y la realidad son el hilo conductor de la crónica, tomando elementos de la literatura para la construcción de una historia; sus límites estilísticos convergen en no sobrepasar a la ficción. A pesar de estas restricciones la crónica ofrece una amplia gama de posibilidades. Es uno de los géneros que más ha influido en el desarrollo de la escritura en América Latina y en Colombia, desde los Cronistas de Indias, El Carnero, el Modernismo, el Boom latinoamericano, hasta los denominados Nuevos Cronistas de Indias.

Para el caso colombiano, el periodismo de diarios nació con el Papel periódico de Santa Fe de Bogotá , dirigido por el periodista cubano Manuel del Socorro Rodríguez. Desde un principio tuvo fuertes nexos con la política. Donaldo Alonso Donado Viloria, en su libro Crónica anacrónica. Un estudio sobre el surgimiento, auge y decadencia de la crónica periodística en Colombia, plantea que: "En Colombia, el Estado, los partidos y la prensa tuvieron el mismo origen, pasaron los mismos avatares, se confundieron e imbricaron de tal manera que no es posible hablar de uno sin referirse a los otros dos (Donado, 54). Esta relación marcó la forma en la que se escribían los periódicos, con una prosa panfletaria y opinativa. La prensa mantuvo el esquema, de servicio al partido al que pertenecían, hasta finales del siglo XIX. La última década del XIX y la primera del XX, en Colombia, transcurrieron con un escenario en el que dominaban guerras, dictaduras, censuras de prensa, la pérdida de Panamá; todos estos sucesos condicionaron el desarrollo del periodismo que estaba muy lejos del estilo informativo que conocemos hoy. 
El periodismo informativo nació de la Revolución Industrial y predominó durante la última mitad del siglo XIX. Es un relato de origen telegráfico, denominado noticia. La industrialización, el desarrollo de las agencias internacionales, la aparición de grandes diarios en las ciudades ayudaron a su desarrollo. El modelo empleado buscaba responder unas preguntas básicas: qué, quién, cómo, cuándo, dónde, y presentaba la información en un esquema denominado "pirámide invertida ${ }^{14 "}$. Este esquema subvierte el orden tradicional de las narraciones literarias en las que, normalmente, se acumula tensión para el final.

En este período de finales del siglo XIX y principios del XX aparecen dos figuras fundamentales: el reporter ${ }^{15}$ y la interview ${ }^{16}$, introducidas por Carlos Martínez Silva, fundador del periódico El Correo Nacional, en 1890. Martínez Silva fue uno de los primeros en romper las costumbres de los periódicos partidistas. Ésos no permitían una condición básica del periodismo informativo: la objetividad.

Los despachos telegráficos, la base en la construcción de las noticias, tenían casi siempre un párrafo. La poca información se debía a la precariedad técnica del telégrafo; en él, sólo podían transmitirse, a costos muy altos, mensajes cortos, en Código Morse, descifrados por los telegrafistas.

El telégrafo representó una gran ruptura; antes, la información llegaba por carta y se demoraba meses para llegar a su destino. Esta modernización apoyó la incorporación de América Latina al mercado internacional, por lo que se produjo una modernización social. Los lectores, con el telégrafo, se sentían insertados en una sociedad universal. Pero no todo fue bueno con la aparición del periodismo informativo, por ejemplo, los

14 La fórmula de este tipo de presentación se basa en la construcción de un primer párrafo o lead, en el que se resumen los datos más importantes. Luego se van incorporando párrafos en orden de interés decreciente.

15 El reporter es el periodista que ya no se fundamenta en las informaciones telegráficas y tampoco se dedica a la prosa partidista; en cambio, sale a la calle a buscar las noticias, investiga, reportea. Esta palabra se adaptó al español y se convirtió en reportero y es el origen de la palabra reportería.

16 El origen de la entrevista, las primeras transcripciones de diálogos en la prensa. literatos se quejaban de un estilo regido, dominado por la eficiencia y la productividad.

Para romper con este esquema fue definitivo el trabajo de los cronistas judiciales, quienes adornaban el relato con descripciones de los personajes, del ambiente, del lugar, inclusive se atrevían a hacer cometarios jocosos; este tipo de periodismo, practicado en la primera década del siglo XX, fue heredero de la crónica literaria y los cuadros de costumbres del siglo XIX. Este estilo narrativo directo, más cercano al habla popular, sólo estaba permitido a los redactores judiciales, a los cables de agencias, y se alejaba de la retórica del periodismo de ideas.

En los años 1920 se vivía una transformación en el país. Se construían puentes, carreteras, ferrocarriles, fábricas, se consolidaron las exportaciones de café, el río Magdalena comunicó a sectores del país antes incomunicados. Aparecieron tertulias como la del café Windsor, que reunía a poetas, políticos, negociantes. Algunos escrito res y reporteros tenían una formación literaria. Ellos fueron vitales para la transformación de la prensa en Colombia y el surgimiento y desarrollo de géneros como la crónica y el reportaje.

Esa formación de los escritores, que les permitió explorar y consolidar sus maneras narrativas, es analizada por Julio Ramos, en su texto Desencuentros de la modernidad en América Latina. Literatura y política en siglo XIX, al afirmar que la crónica es "un lugar privilegiado para precisar la heterogeneidad del sujeto literario" (Ramos, 84). Ramos plantea unas reflexiones de los escritores que intervinieron en la crónica y cómo esta forma de escritura ayudó a explorar su estilo y les permitió relacionarse con la realidad; específicamente se centra en el caso de Rubén Darío, mientras fue corresponsal del diario La Nación, de Buenos Aires, Argentina, a quien cita: "En ese periódico comprendí a mi manera el manejo del estilo"; en este caso el periódico se convierte en una posibilidad de modernización literaria, los autores conciben una nueva manera de trabajar, ya no con reflexiones interiores como lo hacían con la poesía. En ese momento, a partir de su trabajo en los periódicos, necesariamente requerían del contacto con el exterior. Estos autores tienen 
reflexiones interiores con sus poemas y exteriores con su trabajo periodístico; las dos visiones, necesariamente, produjeron una renovación en su trabajo.

Además, los periódicos se convirtieron en una vitrina para conocer el trabajo de autores europeos, así lo hicieron los grandes periódicos americanos. El mercado editorial de América era aún incipiente, no se contaba con un público que sintiera la necesidad de comprar libros, no se había conformado una industria editorial, por eso los periódicos fueron una manera para la democratización de la escritura y para la difusión de las ideas y autores de vanguardia en Europa.

El trabajo de los literatos en los periódicos fue metódico, algunos se ganaban la vida con el periodismo, pero ni siquiera frente a la inmediatez traicionaron su compromiso con la palabra. Justamente, la participación de hombres como Rubén Darío y José Martí ayudó a superar los condicionamientos del lenguaje tipográfico. Hay una forma periodística y al mismo tiempo literaria, la crónica, que es una forma de escritura altamente estilizada.

En la crónica es importante analizar la confluencia entre el periodismo y la literatura, una relación estrecha, unos lazos que las han emparentado y enriquecido. Ese vínculo se hace más claro en el Nuevo Periodismo, que los norteamericanos dicen haber inventado, pero que ya estaba latente en la obra de Daniel Defoe, en el Diario del año de la peste; en la de José Martí y, más contemporáneamente, en el Relato de un náufrago, de Gabriel García Márquez. Este tipo de periodismo se vale de unas técnicas similares a las de la literatura, como contar el relato escena por escena; el manejo del tiempo y la tensión para crear atmósferas y dar cuenta de los hechos que los ocupan. Inclusive, ambos son construcciones del lenguaje y a él se deben. El periodismo narrativo tiene el compromiso con la información, pero además con el componente estético.

Por todo esto es importante el estudio del desarrollo de la escritura en América Latina con la catalizadora influencia de la crónica en la que propongo unos momentos fundamentales:

\section{Cronistas de Indias}

La crónica nació en América con la llegada de los llamados Cronistas de Indias, normalmente sacerdotes que venían a catolizar a los nativos y que registraban lo que veían en el Nuevo Mundo. En el análisis de sus textos están los gérmenes del desarrollo de este género en América.

\section{El carnero, primera crónica americana}

El carnero inaugura la crónica de ciudad, se detiene en las costumbres locales, registra un período temporal de una comunidad determinada, con las noticias políticas, crímenes famosos, pestes, costumbres y escándalos.

\section{El Nuevo periodismo es argentino. Ope- ración masacre, de Rodolfo Walsh}

Aunque los norteamericanos dicen haber inventado el Nuevo Periodismo en 1960, para los argentinos el creador es Rodolfo Walsh, con su novela de no ficción Operación masacre, que relató los hechos ocurridos en 1956, cuando se presentó un contra-golpe militar fallido a la dictadura. En un terreno baldío de la provincia José León Suárez, de Buenos Aires, fueron fusilados varios civiles sospechosos de hacer parte del levantamiento. A casi seis meses del hecho, alguien le dijo a Rodolfo Walsh que un fusilado vivía. Gracias a la investigación, Walsh descubrió que había siete sobrevivientes, los contactó y contó su historia.

\section{Luis Tejada, cuando la crónica se parece al ensayo}

La obra de Luis Tejada se concentra en las crónicas, pequeños fragmentos cotidianos de la realidad, que tratan el análisis de temas y personajes que no estaban en la primera página de los periódicos. Su obra es genuina, sobria, divertida, pero también reposada y erudita, que trata temas desde ángulos inexplorados, muy parecidos a la concepción de ensayo que planteaba Montaigne.

\section{Estética de lo feo. Roberto Arlt y José An- tonio Osorio Lizarazo}

Dentro de la crónica en América Latina existen dos casos fundamentales para concebir la 
transformación de las ciudades y la vida de la gente en las calles; se trata del argentino Roberto Arlt y del colombiano José Antonio Osorio Lizarazo, dos escritores que vivían sus historias, con una estética que no es entendida desde la concepción tradicional, con esa percepción o apreciación de la belleza, con lo elegante, con la armonía, con lo agradable a la vista; al contrario, la planteada es una "estética de lo feo".

\section{Rubén Darío y José Martí, la influencia de la crónica en el desarrollo del Moder- nismo}

La mayor parte de la obra escrita por José Martí y Rubén Darío es una obra recogida en periódicos, sin embargo, este tipo de textos no ha sido analizado. Los gérmenes del modernismo y de las posibilidades de ampliar las concepciones estéticas de sus poemas se encuentran en los relatos periodísticos que ambos publicaron en la prensa durante años.

\section{La crónica en García Márquez y su in- fluencia en el Boom Latinoamericano}

El caso de Gabriel García Márquez y de otros integrantes del llamado Boom Latinoamericano es muy similar al de Darío y Martí; estos escritores encontraron en la prensa una forma de ganarse la vida, de "mantener la mano caliente" y de desarrollar estructuras narrativas que nutrieron profundamente sus esquemas literarios.

\section{La época dorada de la crónica en Colombia}

Entre 1910 y 1960 se produjo una eclosión en el periodismo colombiano, en especial en el género de la crónica que alcanzó los máximos niveles de desarrollo, que no volvieron a lograrse en el siglo XX y que apenas ahora vuelven a tener el vigor y la constancia de esta época definitiva para la historia del periodismo colombiano.

\section{La crónica, un ensayo con acento mexicano}

Es importante analizar la importancia y la influencia que ha tenido y tiene la crónica que se produce desde México, con dos figuras relevan- tes que convierten sus textos en breves ensayos que iluminan la realidad; son los casos de Carlos Monsivais y Juan Villoro.

\section{Los Nuevos Cronistas de Indias}

El programa Nuevos Cronistas de Indias es una idea de la Fundación Nuevo Periodismo Iberamericano, que los define como: "Exploradores contemporáneos, viajan por los territorios urbanos y rurales de Hispanoamérica, para descubrir con el rigor de la reportería y contar con voz propia las historias tiernas, terribles y también asombrosas de los múltiples nuevos mundos que conviven en nuestras sociedades desiguales". Entre los más destacados están: Julio Villanueva Chang, Juan Pablo Menéses, Leila Guerriero, Alberto Salcedo Ramos y José Alejandro Castaño.

\section{Referencias bibliográficas}

Boyton, Robert S (2005). El taller de Gay Talesse. En: El Malpensante. Número 65. 16 de septiembre - 31 de octubre. Bogotá.

Capote, T. (1996). A Sangre fría. Barcelona: Noguer.

Defoe, D. (1996) Diario del año de la peste. España: Seix Barral.

Defoe, D. (1977) Robinson Crusoe. México: Aguilar.

Donado, D. (2003) Crónica anacrónica. Un estudio sobre el surgimiento, auge y decadencia de la crónica periodística en Colombia. Bogotá: Editorial Panamericana.

Eloy Martínez, T. (2006). La otra realidad. Antología. México: Fondo de Cultura Económica.

Entrevista a Oriana Fallaci. En: revista Time. 20 de octubre de 1975.

Faulkner, W. Entrevista tomada de: ww.ciudadseva.com/ textos/teoria/opin/faulkner.htm - 55k. Recuperada el 7 de noviembre de 2008.

García Márquez, G. (2000) Relato de un náufrago. Bogotá: Editorial Norma.

Genette, G. (1991). Ficción y dicción. Madrid: Lumen.

Gordimer, N. (1997) Agenda cultural Alma Máter. Periodismo y narración. N. 129. Febrero de 1997. 
Gutiérrez Girardot, Rafael (1982). La literatura colombiana en el siglo XX. En: Manual de Historia de Colombia. Tomo III. Bogotá: Procultura S. A. Instituto Colombiano de Cultura.

Hoyos, J. J. (2003) Literatura de urgencia. Medellín: Universidad de Antioquia, Legado del Saber, Vol. 13.

Hoyos, J. J. (2003). Escribiendo historias el arte y el oficio de narrar en el periodismo. Medellín: Editorial Universidad de Antioquia.

Rotker, Susana. (2005). La invención de la crónica. México D.F: Fondo de Cultura Económica.

Santamaría, G. (1997) Soy un tramposo, soy un infiltrado en el periodismo. En: Folios. Número 2. pp. 9-13. Medellín: Universidad de Antioquia.

Sierra, Luis G. (2008) Luis Tejada. En: Generación. El Colombiano. (S.F)

Silva Rodríguez, M. (2007). Periodismo y literatura: una cuestión de oficio, pero también de concep- tos. En: Folios. Periodismo para leer. Número: 12-13. pp. 3-6.

Sims, N. (1996). Los periodistas literarios o el arte del reportaje personal. Bogotá: Ancora editores.

Stainer, G y otros. (2000). Extraterritorial: ensayos sobre literatura y la revolución del lenguaje. Argentina: Adriana Hidalgo.

Todorov, Tzvetan.(1988) El origen de los géneros. En: Teoría de los géneros literarios. Madrid: Arco/Libros S.A.

Velásquez Ossa, C.S. y otros. (2005). Manual de géneros periodísticos. Bogotá: Ecoe Ediciones.

Villanueva Chang, J. (1999). Mariposas y murciélagos. Lima: Fondo Editorial de la UPC.

Villanueva Chang, J. (2006). Un día con Julio Villanueva. Aragón: Asociación de la Prensa de Aragón. Congreso de periodismo digital. 